\title{
Of SOLOs and ensembles
}

\author{
Eugene H. Blackstone, MD
}

See related article on pages 70-7.

In this issue of the Journal, Stanger and colleagues ${ }^{1}$ report their experience with the Pericarbon Freedom SOLO prosthetic stentless aortic valve (SORIN SpA, Milan, Italy). I wish to address 2 aspects of their study: the definition of structural valve deterioration (SVD) as an ensemble of different measures and the related temporal pattern of mean transprosthesis gradient-an ensemble average of the same measure across time (see Stanger and colleagues' Figure $1^{1}$ ).

\section{STRUCTURAL VALVE DETERIORATION}

John Kirklin used to admonish that when one defines a word or phrase, the definition must start with " $\mathrm{X}$ is..." and that one cannot define a word with that word. Interventional cardiologists developing Valve Academic Research Consortium definitions for adverse events associated with transcatheter aortic valve replacement confessed that they could not understand the SVD definition published in surgical guidelines. ${ }^{2,3}$ This definition begins, "Structural valve deterioration includes [not $i s]$...deterioration..." and goes on to use phrases such as "substantial regurgitation or stenosis" without qualifying "substantial." It is little wonder that most surgical reports resort to "valve replacement for SVD," a surrogate event for this ill-characterized mode of progressive bioprosthesis failure.

In their article, Stanger and colleagues ${ }^{1}$ bravely offer a complex definition of SVD that is based on an ensemble of dichotomized echocardiographic criteria, citing Zoghbi and colleagues ${ }^{4}$ in their response to Journal reviewers. No matter how well referenced it may be, however, their definition is flawed. They use these criteria to define a timerelated event, but SVD is not a time-related event; it is a longitudinally evolving process. Echocardiographic measures-mean gradient, velocity, and pressure halftime-represent results of surveillance snapshots of that

From the Department of Thoracic and Cardiovascular Surgery, Cleveland Clinic, Cleveland, Ohio.

Disclosures: Author has nothing to disclose with regard to commercial support.

Received for publication May 4, 2015; accepted for publication May 5, 2015.

Address for reprints: Eugene H. Blackstone, MD, Department of Thoracic and Cardiovascular Surgery, Cleveland Clinic, 9500 Euclid Ave, JJ40, Cleveland,

OH 44195 (E-mail: blackse@ccf.org).

J Thorac Cardiovasc Surg 2015;150:10-1

$0022-5223 / \$ 36.00$

Copyright (C) 2015 by The American Association for Thoracic Surgery

http://dx.doi.org/10.1016/j.jtcvs.2015.05.017 process across time, not a biologic event that happens at a moment in time. ${ }^{5}$ Even if arbitrary thresholds of an ensemble of these continuous variables are used to characterize SVD, one cannot know when these thresholds were crossed. At best, these are "interval censored" data.

That said, in a given series of echocardiographic measurements, at what point should the bioprosthesis be replaced (or a valve-in-valve be inserted)? Here, it makes sense to develop objective indications for intervention as SVD progresses. I believe that this is what Stanger and colleagues ${ }^{1}$ are proposing, rather than a definition of SVD. Certainly their criteria remove the fogginess of the current surgical guidelines. They also open the door to dialogue regarding the appropriateness of echocardiographic criteria and whether other variables, such as a patient's symptomatic response or exercise limitation, relate to the degree of SVD progression.

\section{ENSEMBLES}

Echocardiographic surveillance monitors the morphologic and physiologic state of the bioprosthesis and identifies the need for intervention. From a scientific and predictive perspective, however, surveillance echocardiographic data do far more than that; they can be used to characterize the rate of progression of SVD and to identify variables associated with accelerating or reducing that rate. These periodic snapshots of bioprosthesis deterioration constitute longitudinal data with repeated measures across time.

The first objective of longitudinal analysis of echocardiographic data is to derive an ensemble average of continuous variables (eg, gradient) and ordinal variables (eg, regurgitation grade). This is challenging for several reasons. Variability of values within a given patient's data, as well as among patients in a cohort, must be taken into account. These data are often messy. Echocardiograms are not performed at the same intervals (although Stanger and colleagues ${ }^{1}$ have grouped measurements in temporal windows in their Figure 1), and the number of echocardiograms per patient varies depending on duration and completeness of follow-up, intervention on the prosthesis, or death. Despite the heterogeneity of the data, a timerelated ensemble pattern needs to emerge. The statistical models and software to identify this ensemble temporal pattern are still primitive and require collaboration with a 
statistician well-versed in so-called mixed (often nonlinear) models. Stanger and colleagues' Figure $1^{1}$ does not characterize the temporal pattern of the transprosthesis gradient.

The second objective is to identify variables that modulate the underlying temporal pattern. What accelerates the SVD process? What slows it down? Detecting the effect of such variables depends in part on the range covered by important risk factors such as age. The narrow age range in the SOLO cohort (74 \pm 8.7 years) may preclude identifying an effect of age. Naturally, it also depends on number of patients with multiple surveillance echocardiograms and the extent of follow-up. Statistical methods and software to address risk factor identification are still primitive, and Stanger and colleagues ${ }^{1}$ do not attempt it!

The third, and most clinically important, objective is to determine how evolving longitudinal data affect risk of events such as mortality. For example, the apparent decreased risk of reoperation for SVD in elderly patients may be due to a reluctance to operate despite echocardiographic indications. Techniques for jointly modeling a longitudinal sequence of data and the risk of an event are nascent. Johnston and colleagues ${ }^{6}$ have to some extent attempted to tackle this deceptively simple problem.

The final objective is to develop risk factor-modulated ensemble averages from an ensemble of correlated echocardiographic variables - the multivariate longitudinal data analysis problem. This is an unsolved challenge!

Stanger and colleagues' description ${ }^{1}$ of SVD after SOLO bioprosthesis implantation introduces an ensemble of objective measurements for monitoring bioprosthesis deterioration and assessing the need for intervention. The ensemble average of the longitudinal gradient is less well characterized, but this has provided an opportunity to comment on evolving methods for better analysis and interpretation of longitudinal surveillance data.

\section{References}

1. Stanger O, Bleuel I, Gisler F, Göber V, Reineke S, Gahl B, et al. The Freedom Solo pericardial stentless valve: single-center experience, outcomes, and long-term durability. J Thorac Cardiovasc Surg. 2015;150:70-7.

2. Akins CW, Miller DC, Turina MI, Kouchoukos NT, Blackstone EH Grunkemeier GL, et al. Guidelines for reporting mortality and morbidity after cardiac valve interventions. Eur J Cardiothorac Surg. 2008;33:523-8.

3. Vahanian A, Alfieri O, Andreotti F, Antunes MJ, Baron-Esquivias G, Baumgartner $\mathrm{H}$, et al; ESC Committee for Practice Guidelines (CPG); Joint Task Force on the Management of Valvular Heart Disease of the European Society of Cardiology (ESC); European Association for Cardio-Thoracic Surgery (EACTS). Guidelines on the management of valvular heart disease (version 2012): the Joint Task Force on the Management of Valvular Heart Disease of the European Society of Cardiology (ESC) and the European Association for Cardio-Thoracic Surgery (EACTS). Eur J Cardiothorac Surg. 2012;42:S1-44.

4. Zoghbi WA, Chambers JB, Dumesnil JG, Foster E, Gottdiener JS, Grayburn PA et al; American Society of Echocardiography's Guidelines and Standards Committee; Task Force on Prosthetic Valves; American College of Cardiology Cardiovascular Imaging Committee; Cardiac Imaging Committee of the American Heart Association; European Association of Echocardiography; European Society of Cardiology; Japanese Society of Echocardiography; Canadian Society of Echocardiography; American College of Cardiology Foundation; American Heart Association; European Association of Echocardiography; European Society of Cardiology; Japanese Society of Echocardiography; Canadian Society of Echocardiography. Recommendations for evaluation of prosthetic valves with echocardiography and Doppler ultrasound: a report from the American Society of Echocardiography's Guidelines and Standards Committee and the Task Force on Prosthetic Valves, developed in conjunction with the American College of Cardiology Cardiovascular Imaging Committee, Cardiac Imaging Committee of the American Heart Association, the European Association of Echocardiography, a registered branch of the European Society of Cardiology, the Japanese Society of Echocardiography and the Canadian Society of Echocardiography, endorsed by the American College of Cardiology Foundation, American Heart Association, European Association of Echocardiography, a registered branch of the European Society of Cardiology, the Japanese Society of Echocardiography, and Canadian Society of Echocardiography. J Am Soc Echocardiogr. 2009;22:975-1014. quiz 1082-4.

5. Blackstone EH. Breaking down barriers: helpful breakthrough statistical methods you need to understand better. J Thorac Cardiovasc Surg. 2001;122:430-9.

6. Johnston DR, Soltesz EG, Vakil N, Rajeswaran J, Roselli EE, Sabik JF III, et al Long-term durability of bioprosthetic aortic valves: implications from 12,569 implants. Ann Thorac Surg. 2015;99:1239-47. 